\section{Oral health company wins high global rating again}

Oral health company GC Corporation has ranked second in the Quality Management Level Research in Japan for 2018, which is conducted by the Union of Japanese Scientists and Engineers (JUSE) and sponsored by Nikkei Inc.

The results of the tenth edition were announced on 28 November 2018 and GC Corporation was ranked second.

Among the top ten companies from the overall ranking were popular names such as Konica Minolta, Inc., Canon Inc. and NEC Corporation.

GC Corporation said it was proud of being the only company ranked in top ten for five consecutive years.

The firm's long-term targets to assess its corporate quality and conduct a Global Customer Satisfaction Survey are highly appraised as the basis for continued improvement.

Based on these efforts, GCC received the following evaluations from the Quality Management Level Research - first in Dissemination of Quality Management, second in Commitment of Top Management, third in Creation of Customer Value \& Cultivation of Human Resources for Realisation of Quality Management, fifth in Collaboration Capability among Departments and eighth in Establishment and Thorough Implementation of a Process.

More information is available at www.gceurope.com or by emailing marketing@gc.dental.

\section{Defend against disaster}

The effects of incidents such as fires are more damaging than you might imagine. Not only do you have the property to worry about, but what about the loss of patient data?

Ensure your practice keeps sensitive patient images safe by choosing PROPACS from PRO Diagnostics UK.

A cloud based, highly encrypted storage solution for images, PROPACS not only stores images safely but can also protect said images from cyber threats such as viruses, malware and hackers. This means that even when the unspeakable happens your patient images will be ready when you need them.

Don't let a disaster destroy your data. Choose PROPACS.

More information is available by visiting www.prodiagnostics. co.uk or emailing sales@prodiagnostics.co.uk.

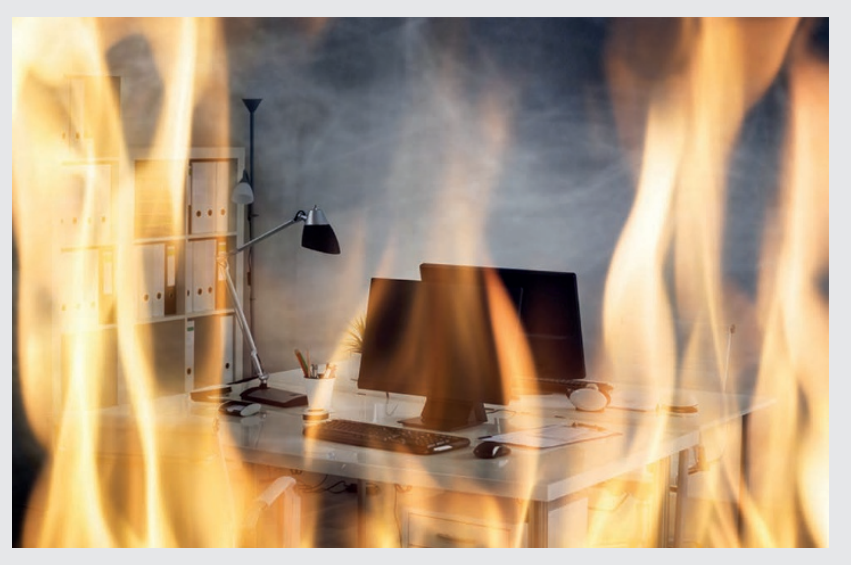

\section{Dental care at its best}

Periodontal scaling has never been easier or more comfortable than with the $\mathrm{W} \& \mathrm{H}$ range of cost-effective piezo scalers, including the Pyon 2 and the Tigon.

W\&H piezo scalers not only feature a ring of LED lights that offer superior visibility within the oral cavity, but they can also be customised with W\&H's extensive range of high quality tips. These are suitable for a variety of indications, such as prophylaxis, periodontics, endodontics, implant maintenance and restorative work.

Designed for ultimate ease-of-use, the Tigon enables practitioners to increase or reduce the power of the scaler and the flow volume of the coolant. This ensures patients experience nothing but truly comfortable and time-efficient dental care.

More information can be found by visiting www.wh.com/ en_uk, calling 01727874990 or emailing office.uk@wh.com.
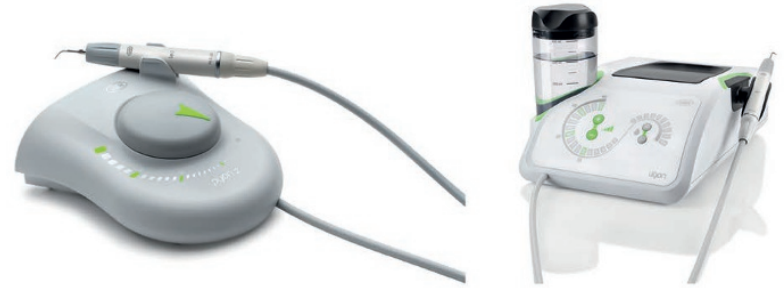

\section{All patients covered}

Amongst the quality product portfolio from Wisdom Toothbrushes are the No. 1 selling rubber interdental brushes in the UK - the Wisdom Clean Between Interdental Brushes. These brushes are clinically proven to reduce gingival disease.

The Wisdom Clean Between Easy Slide Tensioning Flossers featuring a Waveform Tension Control System are another favourite. The floss harps hold the silk-like tape taut between two arms for effortless, comfortable cleaning between the teeth.

Other solutions include the Wisdom Pro-flex Interdental Brushes with a unique flexible hinge and curved profile, the Wisdom Easy Flosser with PTFE tape and the Wisdom Interproximal Brush, ensuring all patients' needs are covered.

More information is available by visiting www.wisdomtoothbrushes.com or calling 01440714800 .
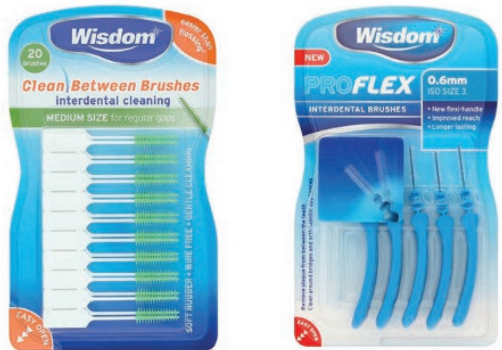